\title{
Differentiation of Peritubular Myoid-Like Cells from Human Induced Pluripotent Stem Cells
}

\author{
Meghan Robinson ${ }^{1}$, Luke Witherspoon ${ }^{2,3}$, Stephanie Willerth ${ }^{4-6}$, \\ Ryan Flannigan ${ }^{1,2,7}$
}

1) Vancouver Prostate Centre, Vancouver, British Columbia

2) Department of Urologic Sciences, University of British Columbia, Vancouver, British Columbia, Canada

3) Department of Urology, The Ottawa Hospital, Ottawa, Ontario, Canada

4) Division of Medical Sciences, University of Victoria, Victoria, British Columbia, Canada

5) Department of Mechanical Engineering, University of Victoria, Victoria, British Columbia, Canada

6) School of Biomedical Engineering, University of British Columbia, Vancouver, British Columbia, Canada

7) Department of Urology, Weill Cornell Medicine, New York, NY, USA

Meghan Robinson: mrobinson@prostatecentre.com; Luke Witherspoon: 1witherspoon@toh.ca, Stephanie Willerth: willerth@uvic.ca

\section{CORRESPONDING AUTHOR}

Ryan Flannigan, MD

ryan.flannigan@ubc.ca

Phone number: 604-875-5003

Department of Urologic Sciences, University of British Columbia, Vancouver, British Columbia

Gordon \& Leslie Diamond Health Care Centre

Level 6, 2775 Laurel Street

Vancouver, BC Canada V5Z 1M9 


\section{ABSTRACT}

Spermatogenesis is a complex process requiring intricate cellular interactions between multiple cell types to produce viable sperm. Peritubular myoid cells (PTMs) are smooth muscle cells that line the seminiferous tubules and play a critical role in sperm production by providing mechanical support and molecular signaling factors. In vitro investigation of their contribution to spermatogenesis and their dysfunction in infertility is currently limited by the rare accessibility of human testicular tissue for research. Therefore, this study set forth to generate an alternative source of PTMs using human induced pluripotent stem cells (hiPSCs) - adult cells that have been reprogrammed into a pluripotent state, making them capable of indefinite expansion and the regeneration of any cell type in the body. PTMs and Leydig cells arise from a common progenitor, so we hypothesized that PTMs could be derived by modifying an existing differentiation protocol for Leydig cell differentiation from hiPSCs. These hiPSC-derived cells, or hPTMs, were characterized and compared to hiPSC-derived Leydig cells (hLCs) and human primary Sertoli cells as a negative control. Our findings show that the substitution of the molecular patterning factor Platelet-Derived Growth Factor Subunit B (PDGF-BB) for Platelet-Derived Growth Factor Subunit A (PDGF-AA) in a molecule-based differentiation protocol for deriving Leydig-like cells, is sufficient to derive peritubular myoid-like cells. This study describes a method for generating PTM-like cells from hiPSCs. These cells will allow for ongoing understanding of the cellular interactions required for normal spermatogenesis in an in vitro setting.

\section{KEY WORDS}

Human Induced Pluripotent Stem Cells, Peritubular Myoid Cell, Leydig Cell, Cell Differentiation, Infertility, Platelet-Derived Growth Factor, Cell Culture, Testicular Cancer 
bioRxiv preprint doi: https://doi.org/10.1101/2021.06.04.447123; this version posted July 13, 2021. The copyright holder for this preprint (which

was not certified by peer review) is the author/funder, who has granted bioRxiv a license to display the preprint in perpetuity. It is made available under aCC-BY-ND 4.0 International license.

In vitro Differentiation of Peritubular Myoid Cells

\section{INTRODUCTION}

Infertility affects approximately $15 \%$ of couples, with male factors contributing to $50 \%$ of cases.(Jarvi, et al., 2015) Development of treatments is hampered due to our limited understanding of the underlying mechanisms leading to this condition. One cell population implicated in infertility are the peritubular myoid cells (PTMs). These cells, in combination with Sertoli cells, constitute a barrier surrounding the seminiferous tubules. A frequent finding on cellular histology of infertile males are defects in the architecture of this barrier, suggesting a dysregulation in its formation or regulation,(Welter, et al., 2013) and consequently the local spermatogenic microenvironment.(Mayerhofer, 2013) PTMs occupy the boundary separating the interstitial Leydig cell compartment from the germ cell tubular compartment, and this strategic anatomic position suggests involvement in the regulation of multiple testicular cell populations. Despite their importance, PTMs remain poorly characterized.

Most of our understanding of PTMs comes from rodent knock-out models and rodent cell culture studies. These in vitro and in vivo studies have shown that PTMs are responsive to androgen stimulation, as evidenced by increased secretion of Sertoli cell regulatory factors(Skinner and Fritz, 1985) and the SSC self-renewal factor GDNF,(Chen, et al., 2016) and are vital to Leydig cell development and function.(Norton and Skinner, 1989, Welsh, et al., 2012) However, the comparative simplicity of the tubular wall architecture in rodents infers that PTM functionality may not be comparable to human PTM functionality.(Mayerhofer, 2013) Therefore, researchers have recently turned to in vitro and biopsy studies of human PTMs to provide greater insight into their nature and regulation.(Mayerhofer, 2013) However, accessibility to testis biopsies for research is limited to specialized clinical laboratories. 


\section{In vitro Differentiation of Peritubular Myoid Cells}

Advancing our understanding of PTMs requires a reproducible and accessible cellular model. To this end, human induced pluripotent stem cells (hiPSCs) are an attractive option for generating

PTMs. These are adult cells which have been reprogrammed into an embryonic-like state by introducing genes essential for pluripotency(Takahashi, et al., 2007). Like embryonic stem cells, they can divide indefinitely and differentiate into all of the specialized cell types of the body.(Liu, et al., 2020)

Peritubular myoid cells share a common progenitor cell type with Leydig cells known as Stem Leydig Cells (SLCs). SLCs are a mesenchymal stem cell type specific to testis tissue, whose lineage has not yet been traced in humans, but in mice are known to arise from a Wilm's Tumor 1 (WT1)-expressing progenitor of the gonadal primordium which gives rise to both SLCs and Sertoli progenitor cells.(Guo, et al., 2020, Liu, et al., 2016) There is accumulating evidence that Sertoli cell-secreted Platelet-Derived Growth Factor-AA (PDGFAA) and Platelet-Derived Growth Factor-BB (PDGFBB) are important patterning factors delineating Leydig cell and PTM cell fates from SLCs. Mice PDGFAA Receptor (PDGFRA) knock-out models fail to produce adult Leydig cells despite exhibiting normal development of SLCs,(Gnessi, et al., 2000) while Sertoli cell Androgen Receptor (AR) knock-out models exhibit reduced PDGFAA production, correlating with a $40 \%$ loss of Leydig cell differentiation.(De Gendt, et al., 2005) In contrast, PDGFBB signaling inhibits Leydig cell differentiation,(Odeh, et al., 2014) and induces a functional phenotype in PTMs,(Chiarenza, et al., 2000) including contractility and secretion of extracellular matrix proteins.(Gnessi, et al., 1993)

Therefore, in this study we hypothesized that substituting PDGFBB in place of PDGFAA into an existing Leydig cell differentiation protocol from hiPSCs(Chen, et al., 2019) would be enough to promote their differentiation into PTMs. We use immunocytochemistry and reverse transcription 


\section{In vitro Differentiation of Peritubular Myoid Cells}

quantitative polymerase chain reaction (RT-qPCR) to show that cells with PTM-like or Leydiglike cell phenotypes and gene expression profiles can be alternatively derived from hiPSCs through the actions of PDGFBB or PDGFAA signaling. This study provides a means of generating PTMlike cells from hiPSCs for in vitro studies.

\section{MATERIALS AND METHODS}

\section{Ethical approval}

Testis biopsy samples were obtained through the University of British Columbia Andrology Biobank, with informed consent for research (CREB approved protocol H18-03543). Experiments using hiPSCs in this study were not subject to ethics approval from the University of British Columbia Clinical Research Ethics Boards or Stem Cell Oversight Committee, since they were derived from somatic cells and not intended for transfer into humans or non-human animals.

\section{Culture of hiPSCs}

The hiPSC line used was the 1-DL-01 line from WiCell.(WiCell, 2021) hiPSCs were expanded on Growth Factor Reduced Matrigel (Corning, 354230) in mTeSR TM-Plus medium (STEMCELL Technologies, 100-0276), and passaged when 90\% confluent using ReLeSR ${ }^{\mathrm{TM}}$ enzyme-free selective passaging reagent (STEMCELL Technologies, 05872) to maintain purity.

\section{Differentiation of Leydig cells from hiPSCs}

Leydig cells were differentiated from hiPSCs as previously described with a modification (Figure 1A).(Chen, Li, Chen, Xi, Zhao, Ma, Xu, Han, Zhao, Ge and Guo, 2019) 


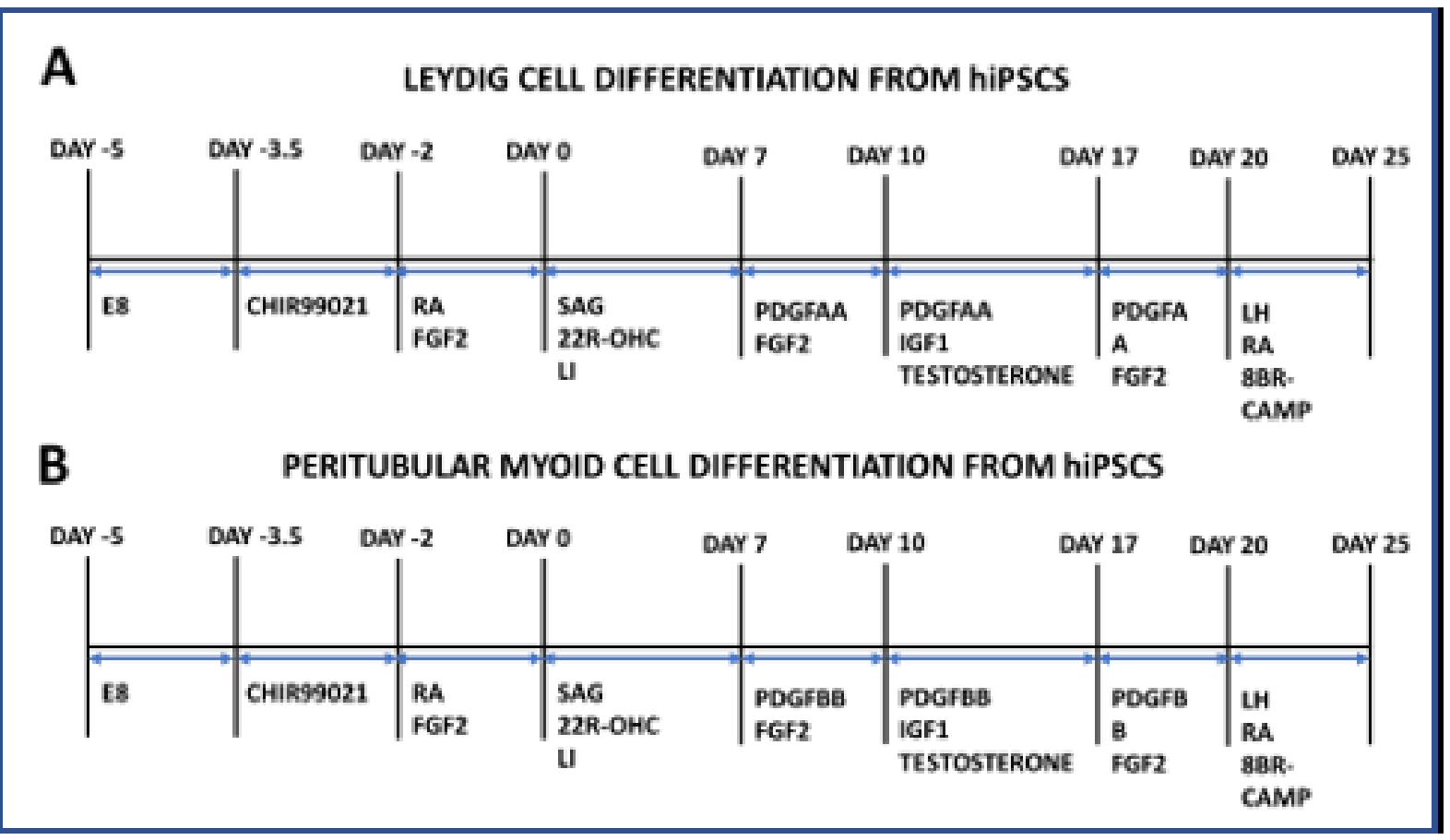

Figure 1. Timelines for differentiating Leydig cells and peritubular myoid cells from human induced pluripotent stem cells (hiPSCs). A) Timeline for differentiating Leydig cells from hiPSCs, based on a previously published protocol, with a modified preliminary step to first derive intermediate mesenchymal stem cells to improve differentiation efficiency. B) Timeline for differentiating peritubular myoid cells from hiPSCs by repeating the Leydig cell differentiation protocol, but substituting PDGFBB for PDGFAA. Abbreviations: $\mathrm{E} 8=$ TeSR-E8 medium, RA $=$ retinoic acid, FGF2 $=$ Fibroblast Growth Factor 2, SAG = Smoothened agonist, 22R-OHC = 22R-hydroxycholesterol, $\mathrm{LI}=$ lithium chloride, $\mathrm{PDGFAA}=$ Platelet-Derived Growth Factor-AA, PDGFBB = Platelet-Derived Growth Factor-BB, IGF1 = Insulin-Like Growth Factor 1, LH $=$ luteinizing hormone, 8BR-CAMP $=8$-bromo-cAMP.

The original protocol yielded $41.5 \%$ Leydig cells, likely because the hiPSCs spontaneously differentiated for 2 days prior to patterning, allowing for endodermal and ectodermal lineage acquisition in addition to mesenchymal. Therefore, we first patterned the hiPSCs with a mesenchymal protocol as previously described.(Lam, et al., 2014) Cells were treated with $5 \mu \mathrm{M}$ 
CHIR99021 (STEMCELL Technologies, 72052) in Roswell Park Memorial Institute Medium 1640 (RPMI 1640, Gibco, 11875-093) for 36 hours, then $1 \mu \mathrm{M}$ all-trans retinoic acid (RA, STEMCELL Technologies, 72262) and 100ng/mL human recombinant Fibroblast Growth Factor 2 (FGF2, STEMCELL Technologies, 78003.1) in RPMI 1640 for 2 days. They were then subjected to the following protocol for Leydig cell differentiation: cells were cultured throughout on Matrigel substrates in Dulbecco's Modified Eagle Medium/Nutrient Mixture F-12 with 15mM HEPES (DMEM/F12, STEMCELL Technologies , 36254) 1X Insulin Transferrin Selenium Liquid Media Supplement (ITS, Millipore Sigma, I13146), 1\% penicillin/streptomycin (Sigma Aldrich, P4333)and 1X GlutaMAX (Thermofisher, 35050079), 1\% bovine serum albumin (BSA, Miltenyi Biotec, 130-091-376) and $5 \mathrm{ng} / \mathrm{mL}$ luteinizing hormone from human pituitary (LH, Sigma, L6420), with media changes every other day. From 0-7 days, $0.2 \mu \mathrm{M}$ Smoothened Agonist (SAG,

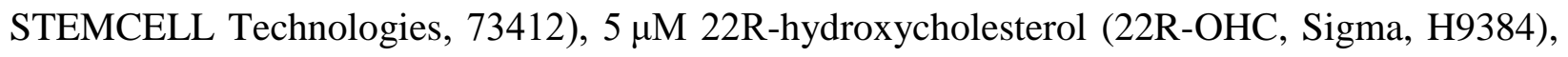
and $5 \mathrm{mM}$ lithium chloride (Sigma, 62476) were added. From 7-10 days, $5 \mathrm{ng} / \mathrm{mL}$ human recombinant Platelet-Derived Growth Factor-AA (PDGF-AA, Peprotech, 100-13A) and 5 ng/mL FGF2 were added. From 10-17 days, 5 ng/mL PDGF-AA, 5 nM Insulin-Like Growth Factor 1 (IGF1, Peprotech, 100-11), and $10 \mu \mathrm{M}$ testosterone (Toronto Research Chemicals, T155010) were added. From days 17-20, 10 ng/mL PDGF-AA and 10 ng/mL FGF2 were added. From days 2025, $5 \mathrm{ng} / \mathrm{mL} \mathrm{LH}$ (total of $10 \mathrm{ng} / \mathrm{mL}$ ), $0.5 \mathrm{mM}$ RA and $1 \mathrm{mM}$ 8-bromo-cAMP (Peprotech, 2354843) were added. On day 25 cells the cells were switched to Leydig Cell Media (Sciencell Research Laboratories, 4511) for expansion, and passaged onto poly-L-lysine (PLL, Sciencell Research Laboratories, 0413) using TrypLE ${ }^{\mathrm{TM}}$ Express Enzyme (Thermofisher, 12604013). 


\section{Differentiation of PTMS from hiPSCs}

PTMs were differentiated from hiPSCs using the above protocol for hiPSC-derived Leydig cells with the modification that PDGF-AA is replaced by human recombinant Platelet-Derived Growth Factor-BB (PDGF-BB, Peprotech, 100-14B, Figure 1B). On day 25 the cells were expanded on PLL-coated plates in DMEM/F12, 1X ITS, 1\% penicillin/streptomycin, 2.5\% fetal bovine serum (FBS, Gibco, 12483-020), 10 ng/mL FGF2, 1 ng/mL human recombinant Leukemia Inhibitory Factor (LIF, STEMCELL Technologies, 78055.1) and $10 \mathrm{ng} / \mathrm{mL}$ human recombinant Epidermal Growth Factor (EGF, STEMCELL Technologies, 78006.1), and passaged using TrypLETM Express Enzyme.

\section{Primary Sertoli cell isolation and culture}

Testicular biopsies were transported to the lab on ice in Hypothermosol@ FRS (STEMCELL Technologies, 07935). They were rinsed three times with Hank's Balanced Salt Solution (HBSS, Millipore Sigma, 55021C), then cut into $1 \mathrm{~mm}^{3}$ pieces with surgical scissors, and digested by Collagenase NB4 (Nordmark Biochemicals, S1745402) at 2PZU / $100 \mathrm{mg}$ tissue, for 5 minutes at $37^{\circ} \mathrm{C}$ and $250 \mathrm{rpm}$. The sample was vigorously shaken and then incubated for a further 3 minutes at $37^{\circ} \mathrm{C}$ and $250 \mathrm{rpm}$. After spinning for 5 minutes at $200 \mathrm{x} \mathrm{g}$, sedimented tubules were rinsed 3 times with HBSS, with spinning at $200 \mathrm{x}$ g for 5 minutes in between each rinse. The sedimented tubules were re-suspended in $0.25 \%$ Trypsin/EDTA (Sigma, T3924) and $0.8 \mathrm{kU} / 100 \mathrm{mg}$ DNase I (Sigma, D4263). The tubules were pipetted 3-5 times with a $5 \mathrm{~mL}$ pipette and incubated for 5 minutes at $37^{\circ} \mathrm{C}$. This step was repeated for a total of 3 incubations. $10 \%$ FBS was added to stop the digestion, and the tubules were filtered through a $70 \mu \mathrm{m}$ filter, then a $40 \mu \mathrm{m}$ filter, and centrifuged for 15 minutes at $600 \mathrm{x}$ g. The cells were sorted into somatic and germ fractions by overnight plating in a single well on a tissue culture-treated 6-well plate. The next day, nonadherent cells were removed (germ cells) and the adherent cells (somatic cells) were expanded on 
PLL-coated plates in a 1:1:1 mixture of Endothelial Cell Growth Medium (Promocell, C-22010), Sertoli Cell Medium (Sciencell, 4521), and Leydig Cell Medium (Sciencell, 4511). Passaging was done using TrypLE Express Enzyme. 36 million cells were used for sorting with the Sertoli cell marker Thy-1 Cell Surface Antigen (THY1/CD90) using a PE-conjugated antibody for

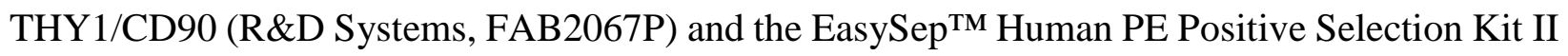
(STEMCELL Technologies, 17664) with EasySep ${ }^{\text {TM }}$ Magnet (STEMCELL Technologies, 18000), as per the manufacturer's instructions, with the following specifications: $3 \mu \mathrm{g} / \mathrm{mL}$ FcR blocker, 3 $\mu \mathrm{g} / \mathrm{mL}$ THY1/CD90 antibody, $75 \mu \mathrm{L} / \mathrm{mL}$ RapidSpheres ${ }^{\mathrm{TM}}, 5$ minutes incubation for separation 1 , and 10 minutes incubation for separations 2 and 3. THY1/CD90+ cells were expanded on PLLcoated plates in Sertoli Cell Medium and passaged with TrypLE ${ }^{\mathrm{TM}}$ Express Enzyme.

\section{Immunocytochemistry}

Cells were fixed for 15 minutes in $4 \%$ paraformaldehyde solution (PFA, Thermo Scientific, J19943-K2), permeabilized for 15 minutes in 0.1\% Triton X-100 (Sigma, X100) in phosphate buffered saline (PBS), and blocked for 2 hours in 5\% normal goat serum (NGS, Abcam, ab7481) in PBS. Primary antibodies were diluted in PBS as follows: anti-Hydroxy-Delta-5-Steroid Dehydrogenase, 3 Beta- And Steroid Delta-Isomerase 1 (HSD3 $\beta$, Novus Biologicals, NB1107844) 1:200, anti-Myosin Heavy Chain 11 (MYH11, Abcam, ab212660) 1:1000, anti-OctamerBinding Protein 4 (OCT4, Abcam, ab184665) 1:500, anti-SRY-Box Transcription Factor 9 (SOX9, Abcam, ab76997) 1:500, anti-GATA Binding Protein 4 (GATA4, Abcam, ab84593) 1:100, anti-Nestin (Millipore, MAB5326) 1:200, anti-Thy-1 Cell Surface Antigen (THY1/CD90, Abcam, ab133350) 1:200, and incubated overnight at $4^{\circ} \mathrm{C}$ in the dark. Cells were rinsed 3 times with PBS for 15 minutes each at $4^{\circ} \mathrm{C}$ in the dark. Goat anti-Rabbit $\mathrm{IgG}(\mathrm{H}+\mathrm{L})$ Highly CrossAdsorbed Secondary Antibody Alexa Fluor 488 (Thermofisher, A-11034) or Goat anti-Mouse IgG 
(H+L) Highly Cross-Adsorbed Secondary Antibody Alexa Fluor 568 (Thermofisher, A-11031) were diluted 1:200 in PBS and incubated with the cells for 4 hours at $4^{\circ} \mathrm{C}$ in the dark. Cells were rinsed another 3 times with PBS for 15 minutes each at $4{ }^{\circ} \mathrm{C}$ in the dark. $4^{\prime}, 6$-diamidino-2phenylindole (DAPI, Abcam, ab228549) was diluted to $2.5 \mu \mathrm{M}$ in PBS and added to the cells for 15 minutes in the dark at room temperature, and then replaced by PBS. Cells were imaged using a Zeiss AXio Observer microscope equipped with laser excitation and fluorescence filters for AlexaFluor 488 and AlexaFluor 568 dyes, and ZEN Blue software. Image processing was done using ImageJ open source software.

\section{Real time quantitative polymerase chain reaction}

Real time quantitative polymerase chain reaction (RT-qPCR) validation was done using PrimePCR ${ }^{\mathrm{TM}}$ Assays (Bio-Rad) with SYBR® chemistry. RNA was extracted using an RNeasy Plus Micro Kit (Qiagen, 74034), and checked for integrity using an Agilent 2200 Tapestation System with High Sensitivity RNA Screentape (Agilent, 5067- 5579), High Sensitivity RNA ScreenTape Sample Buffer (Agilent, 5067- 5580), and High Sensitivity RNA ScreenTape Ladder (Agilent, 5067- 5581). cDNA was generated using iScript ${ }^{\mathrm{TM}}$ Reverse Transcription Supermix (Bio-Rad, 1708840) with a Tetrad2 Peltier Thermal Cycler (Bio-Rad). PrimePCR ${ }^{\text {TM }}$ Primers (BioRad) used were as listed in Table 1. RT-qPCR was done with SsoAdvanced ${ }^{\mathrm{TM}}$ Universal SYBR® Green Supermix (Bio-Rad, 1725270) on a LightCycler96 (Roche). Technical replicates were carried out in triplicate. Analyses was done in Excel and GraphPad Prism Software. Ct values were normalized to Glyceraldehyde-3-Phosphate Dehydrogenase (GAPDH). Outliers were detected using Grubbs' Test, with $\alpha=0.05$. Results of RT-qPCR are presented as the average Relative Quantification $\left(\mathrm{RQ}=2^{-\Delta \Delta \mathrm{Ct}}\right.$ ) values and the upper and lower RQ of the biological replicates. Any undetected samples were given a $\mathrm{Ct}$ value of the maximum number of cycles plus 1 . 
bioRxiv preprint doi: https://doi.org/10.1101/2021.06.04.447123; this version posted July 13, 2021. The copyright holder for this preprint (which was not certified by peer review) is the author/funder, who has granted bioRxiv a license to display the preprint in perpetuity. It is made available under aCC-BY-ND 4.0 International license.

In vitro Differentiation of Peritubular Myoid Cells

Table 1. Amplicon content sequences and Unique Assay IDs for Bio-Rad PrimePCR ${ }^{\mathrm{TM}}$ primer pairs used in real time quantitative polymerase chain reaction (RT-qPCR) assays

\begin{tabular}{|c|c|c|}
\hline Gene & Amplicon Content Sequence & $\begin{array}{l}\text { Bio-Rad } \\
\text { Unique Assay } \\
\text { ID }\end{array}$ \\
\hline ACTA2 & $\begin{array}{l}\text { GCGGCAGTGGCCATCTCATTTTCAAAGTCCAGAGCTACATAACACAGTTTCTCCT } \\
\text { TGATGTCCCGGACAATCTCACGCTCAGCAGTAGTAACGAAGGAATAGCCACGC }\end{array}$ & qHsaCID0013300 \\
\hline AR & $\begin{array}{l}\text { GACTCCTTTGCAGCCTTGCTCTCTAGCCTCAATGAACTGGGAGAGAGACAGCTT } \\
\text { GTACACGTGGTCAAGTGGGCCAAGGCCTTGCCTGGCTTCCGCAACTTACACGTG } \\
\text { GACGACCAGATGGCTGTCATTCAGTACTCCTGGATGGGGCTCATGGTGTTT }\end{array}$ & qHsaCID0007155 \\
\hline GAPDH & $\begin{array}{l}\text { GTATGACAACGAATTTGGCTACAGCAACAGGGTGGTGGACCTCATGGCCCACAT } \\
\text { GGCCTCCAAGGAGTAAGACCCCTGGACCACCAGCCCCAGCAAGAGCACAAGAG } \\
\text { GAAGAGAGAGACCCTCACTGCTGGGGAGTCCCTGCCACAC }\end{array}$ & qHsaCED0038674 \\
\hline HSD3B1 & $\begin{array}{l}\text { CCCAGCATCTTCTGTTTCCTGGTGAGTGATTCCTGCTACTTTGGATGGCCATGAC } \\
\text { GGGCTGGAGCTGCCTTGTGACAGGAGCAGGAGGGTTTCTGGGACAGAGGATCA } \\
\text { TCCGCCTCTTGGTGAAGGAGAAGGAGCTGAAGGAGATCAG }\end{array}$ & qHsaCED0007038 \\
\hline MYH11 & $\begin{array}{l}\text { GCATCTCGTGCCTCTTCTTGCCCTTGTACATGTCGACGATCTTCTCCGAGTAGAT } \\
\text { GGGCAGGTGTTTATAGGGGTTGACCACCACGCAGAAGAGGCCAGAGTACGTAT } \\
\text { ATATTAGCCCTGAGAAGTACCGCTCC }\end{array}$ & qHsaCID0016619 \\
\hline
\end{tabular}

Abbreviations: ACTA2 = Actin Alpha 2 Smooth Muscle, AR = Androgen Receptor, GAPDH = Glyceraldehyde-3-Phosphate Dehydrogenase , HSD3B1 = Hydroxy-Delta-5-Steroid Dehydrogenase, 3 Beta- And Steroid Delta-Isomerase 1 (HSD3ß), MYH11 = Myosin Heavy Chain 11.

Table 1. Amplicon content sequences (amplicon sequence with additional base pairs added to the beginning and/or end of the sequence), and Unique Assay IDs for Bio-Rad PrimePCR ${ }^{\mathrm{TM}}$ primer pairs used for RT-qPCR. 


\section{In vitro Differentiation of Peritubular Myoid Cells}

\section{Statistics}

Statistics were performed using GraphPad Prism software. Each experiment was performed in biological triplicate. For RT-qPCR results, significance was determined by comparing $\Delta C t$ values using a student's unpaired two-tailed t-test, with $\alpha=0.05$.

\section{RESULTS}

To generate PTMs from hiPSCs (hPTMs), we employed a previously established Leydig cell differentiation protocol wherein hiPSCs acquire Leydig-like gene expression and steroidogenic function by way of patterning with growth factors and small molecule agonists of intracellular pathways (Figure 2A)(Chen, et al., 2020). These patterning factors were chosen based on their roles in Leydig cell differentiation in vivo, and validated by their ability to differentiate Leydig cells from SLCs in vitro, thus mirroring normal Leydig cell development from SLCs. To better mimic in vivo differentiation, we modified the protocol slightly by adding a preliminary step to first derive SLC precursor cells known as intermediate mesenchymal stem cells.(Wilhelm, et al., 2007) This step was hypothesized to improve the efficiency of differentiation by inhibiting early acquisition of ectodermal or endodermal lineages. We derived cells using this modified protocol, then substituted PDGFBB for PDGFAA to derive a second population of cells, and compared the resulting phenotypes in terms of gene expression and morphology. For a negative control, we isolated human primary Sertoli cells from a testis biopsy using MACS with an anti-THY1/CD90 antibody (Figure 2B). Sertoli cells are the spermatogenic regulatory cells of the niche. They share a cellular lineage with Leydig cells and PTMs, but have no steroidogenic or smooth muscle character, making them a suitable control for this study. 


\section{Phenotype}

In addition to being a known surface marker of cultured human Sertoli cells,(Chui, et al., 2011)

THY1/CD90 has successfully been used to isolate rat SLCs using Fluorescent Activated Cell Sorting (FACS),(Guan, et al., 2019, Li, et al., 2016) therefore we expected sorted primary THY1/CD90 cell cultures to contain some contaminating SLCs in addition to Sertoli cells. However, the sorted cultures stained uniformly positive for the Sertoli cell-specific marker SOX9 in addition to THY1/CD90 (Figure 2B-C), while the Leydig cell marker HSD3 $\beta$ and peritubular myoid cell marker MYH11 were negative (Figure 2A), confirming a cell population highly enriched for Sertoli cells. The absence of THY1/CD $90^{+}$SLCs may be explained by differences between MACS and FACS techniques, such as the ability with FACS to further sort labeled cell populations based on size and granularity, or differences between rat and human SLC or Sertoli cell expression of THY1/CD90. Interestingly, we also observed Nestin expression in the sorted cells (Figure 2B). Since SOX9 was localized to nuclei, a sign of differentiated Sertoli cells,(Malki, et al., 2005) this was also unexpected. In addition to being associated with differentiating cells, Nestin is a well-known regulator of proliferation,(Bernal and Arranz, 2018) which is shown to resume in adult Sertoli cells under in vitro conditions.(Guo, et al., 2015) While Sertoli cells revert to a proliferative state in vitro, studies show that otherwise their global phenotypes remain stable, in agreement with the nuclear SOX9 localization noted in our cultures.(Guo, Hai, Yao, Chen, Hou, $\mathrm{Li}$ and $\mathrm{He}, 2015)$ 


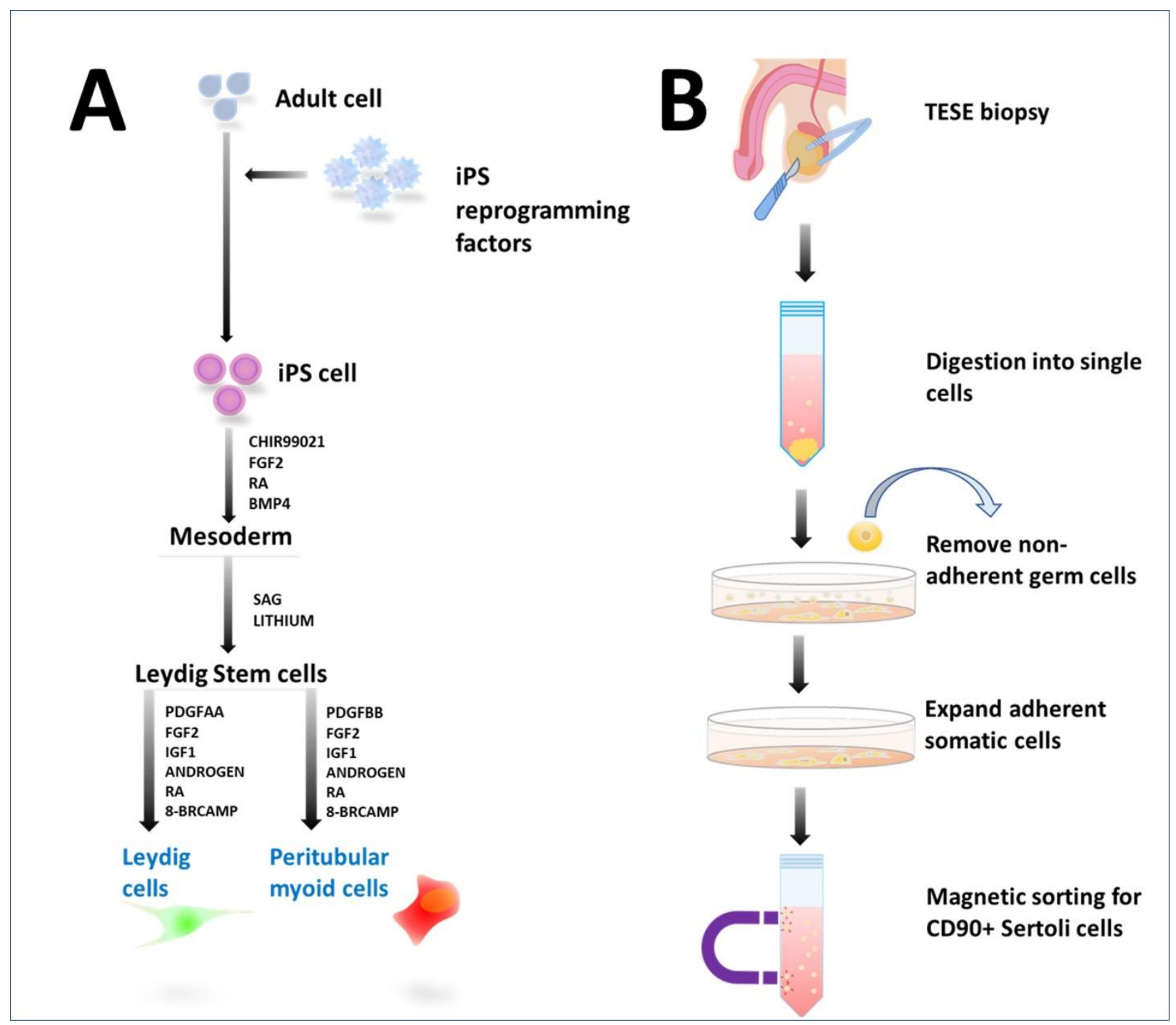

Figure 2. Experimental schematics for deriving Leydig cells and peritubular myoid cells from hiPSCs, and isolating primary Sertoli cells. A) Schematic representing the derivation of an intermediate mesoderm cell fate followed by either Leydig cell or peritubular myoid cell derivation. B) Schematic representing the isolation of primary Sertoli cells from a testicular biopsy by first digesting the biopsy into single cells, followed by removal of germ cells by differential plating, expansion of somatic cells and magnetic sorting. Abbreviations: iPS $=$ induced pluripotent stem, FGF2 = Fibroblast Growth Factor 2, RA = retinoic acid, BMP4 = Bone Morphogenic Protein 4, SAG = smoothened agonist, PDGFAA $=$ Platelet-Derived Growth 


\section{In vitro Differentiation of Peritubular Myoid Cells}

Factor-AA, PDGFBB = Platelet-Derived Growth Factor-BB, IGF1 = Insulin-Like Growth Factor 1 = 8-BRCAMP

= 8-bromo-cAMP, TESE = testicular sperm extraction, $\mathrm{CD} 90=/$ Thy-1 Cell Surface Antigen.

PDGFAA and PDGFBB-derived cells adopted immature Leydig cell-like and PTM-like phenotypes, respectively. PDGFAA-derived cells became spindle shaped whereas PDGFBBderived cells acquired a flat polygonal shape, as expected based on previous descriptions of these cells in culture (Figure 3A).(Losinno, et al., 2012, Tung and Fritz, 1986) Moreover, spontaneous ring formation was noted in PDGFBB-derived cell cultures, a unique characteristic of purified PTMs in culture (Figure 3A).(Mishra, et al., 2012) Immunocytochemistry analysis revealed reactivity for GATA4, a testis-specific transcription factor(Ketola, et al., 2000, Viger, et al., 1998), in both cell types, confirming testis-specific lineages (Figure 3A). The Leydig cell steroidogenic enzyme HSD3 $\beta$ was present only in the PDGFAA-derived cells, while the peritubular myoid cellspecific smooth muscle protein MYH11 was only present in the PDGFBB-derived cells, confirming adoption of either Leydig cell-like or PTM-like phenotypes (Figure 3A).(Mayerhofer, 2013, Ye, et al., 2017) Nestin and CD90/THY1, two genes associated with SLCs,(Guan, Chen, Zhao, Hao, Chen, Ji, Wen, Lin, Ye and Chen, 2019, Ye, Li, Li, Chen and Ge, 2017) were also positive in both cell types (Figure 3B), suggesting that the cells were immature. Positive immunoreactivity for the Sertoli cell marker SOX9 was rare in both cell cultures (Figure 3C), denoting very little contamination by Sertoli-like cells. Likewise, immunoreactivity for OCT4, a pluripotency marker,(Takahashi, Tanabe, Ohnuki, Narita, Ichisaka, Tomoda and Yamanaka, 2007) was rare, indicating a very small presence of contaminating hiPSCs. 
bioRxiv preprint doi: https://doi.org/10.1101/2021.06.04.447123; this version posted July 13, 2021. The copyright holder for this preprint (which was not certified by peer review) is the author/funder, who has granted bioRxiv a license to display the preprint in perpetuity. It is made available under aCC-BY-ND 4.0 International license.

In vitro Differentiation of Peritubular Myoid Cells

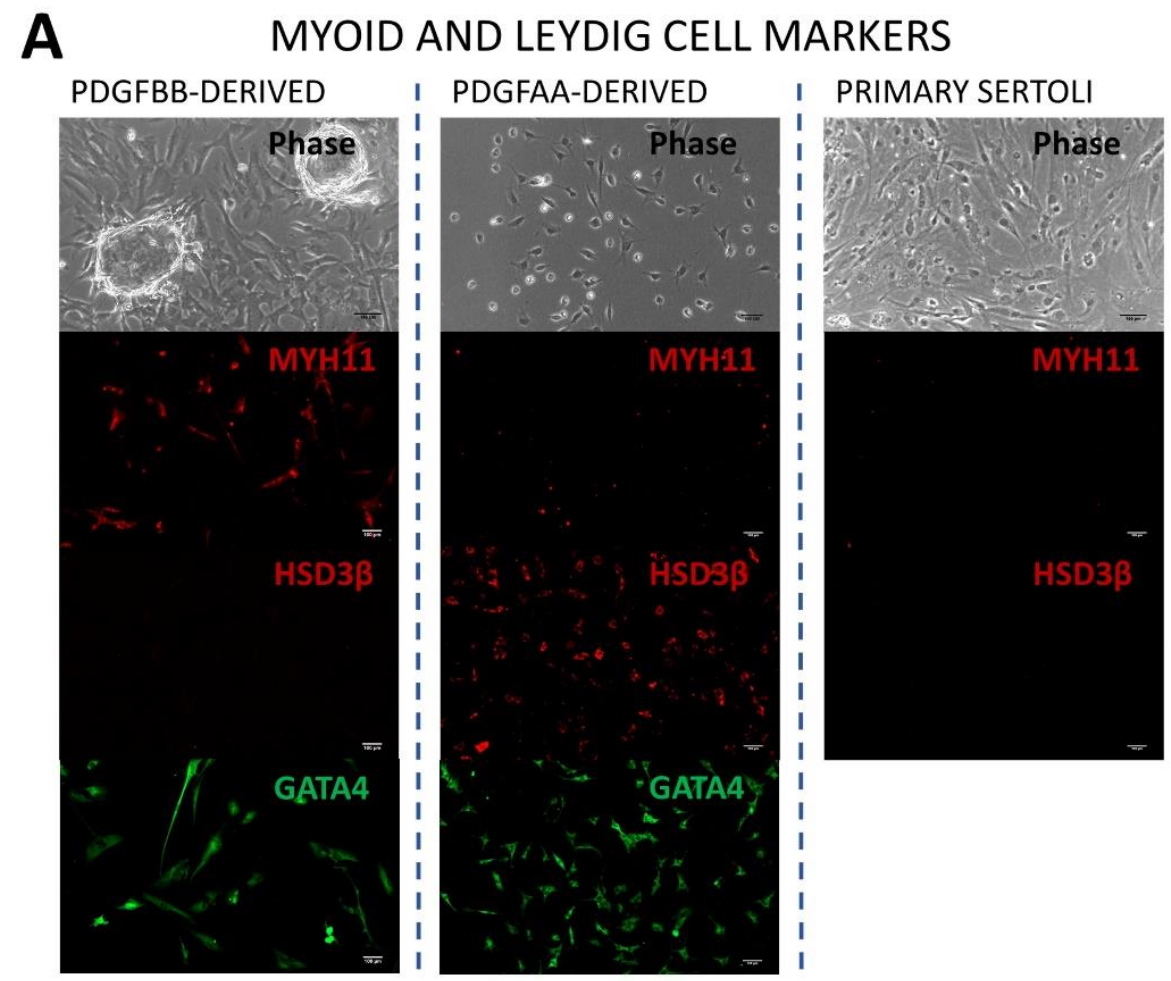

B

PROGENITOR MARKERS

PDGFBB-DERIVED

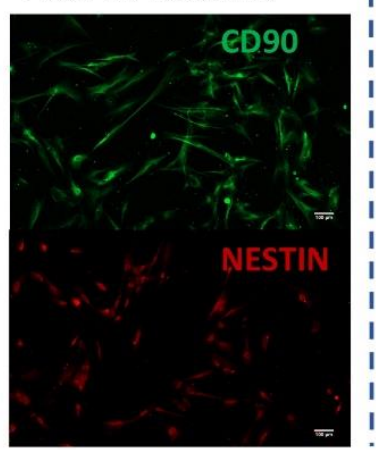

PDGFAA-DERIVED

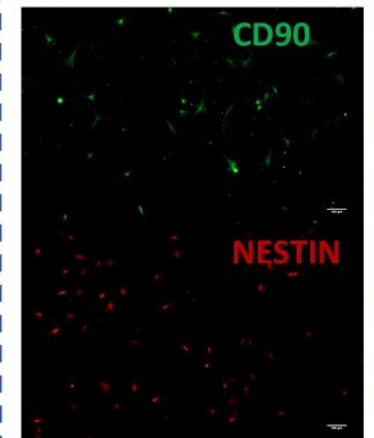

PRIMARY SERTOLI

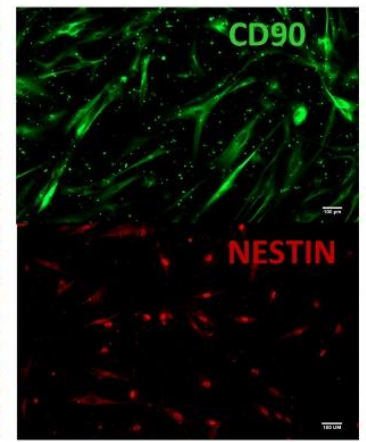

C

hIPSC AND SERTOLI CELL MARKERS
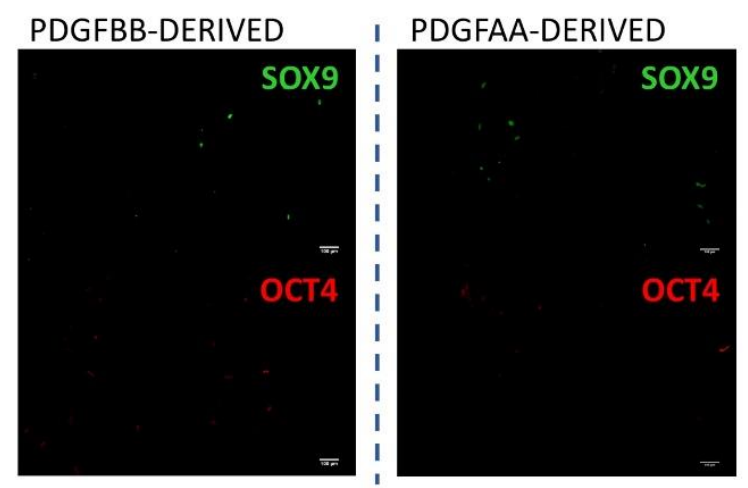

PRIMARY SERTOLI

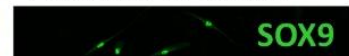


bioRxiv preprint doi: https://doi.org/10.1101/2021.06.04.447123; this version posted July 13, 2021. The copyright holder for this preprint (which was not certified by peer review) is the author/funder, who has granted bioRxiv a license to display the preprint in perpetuity. It is made available under aCC-BY-ND 4.0 International license.

\section{In vitro Differentiation of Peritubular Myoid Cells}

Figure 3: Phenotype characterization of PDGFAA-derived and PDGFBB-derived cells, and the primary Sertoli cell control. A) Peritubular myoid cell and Leydig cell phenotypes: phase contrast images and immunocytochemistry images of the myoid smooth muscle marker MYH11, the Leydig cell steroidogenic enzyme HSD3ß, and the testicular somatic marker GATA4. B) Immature or differentiating phenotypes: the SLC and Sertoli cell marker CD90, and the differentiating cell marker Nestin. C) hiPSC and Sertoli cell phenotypes: the Sertoli cell marker SOX9, and the pluripotency marker OCT4. All scale bars are $100 \mu \mathrm{m}$. Abbreviations: PDGFBB = Platelet-Derived Growth Factor-BB, PDGFAA = Platelet-Derived Growth FactorAA, MYH11 = Myosin Heavy Chain 11, HSD3B = Hydroxy-Delta-5-Steroid Dehydrogenase, 3 Beta- And Steroid Delta-Isomerase 1, GATA4 = GATA Binding Protein 4, CD90 = Thy- 1 Cell Surface Antigen, hiPSC $=$ human induced pluripotent stem cell, SOX9 = SRY-Box Transcription Factor 9.

\section{Gene expression}

Gene expression analysis by RT-qPCR further confirmed distinct Leydig-like and PTM-like profiles in the PDGFAA and PDGFBB-derived cultures (Figure 4A). PDGFBB-derived cells upregulated expression of smooth muscle genes ACTA2 and MYH11 compared to PDGFAAderived cells, by 23-fold [4-114] and 32-fold [6-161]. Compared to primary Sertoli cells, PDGFAA-derived cells upregulated MYH11 4-fold [1-11], whereas PDGFBB-derived cells upregulated MYH11 124-fold [26-623] (Figure 4B). In contrast to their immunocytochemistry profiles, no significant difference in HSD3 $\beta$ was observed between PDGFAA and PDGFBBderived cells, suggesting differences in post-transcriptional regulation (Figure 4B). Nevertheless, compared to Sertoli cells, PDGFAA-derived cells increased gene expression of HSD3 $\beta$ 53-fold [15-190], verifying their steroidogenic phenotype (Figure 4B). Testicular cells rely upon androgen stimulation,(Mayer, et al., 2018, Meroni, et al., 2019, Wang, et al., 2009, Ye, Li, Li, Chen and Ge, 2017) therefore we examined their expression of androgen receptor. PDGFAA-derived cells possessed similar levels of androgen receptor gene expression as Sertoli cells (Figure 4B), while 
PDGFBB-derived cells exhibited greater expression by 3-fold [1-14] (Figure 4B), illustrating the adoption of androgen-dependent phenotypes by both cell types.

A

Gene expression of hiPSC-derived cells:

PDGF-BB compared to PDGF-AA

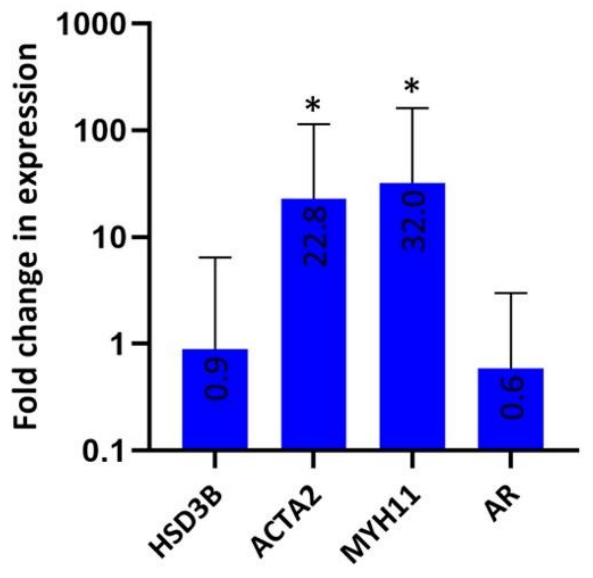

Genes

B

Gene expression of hiPSC-derived cells compared to primary Sertoli cells

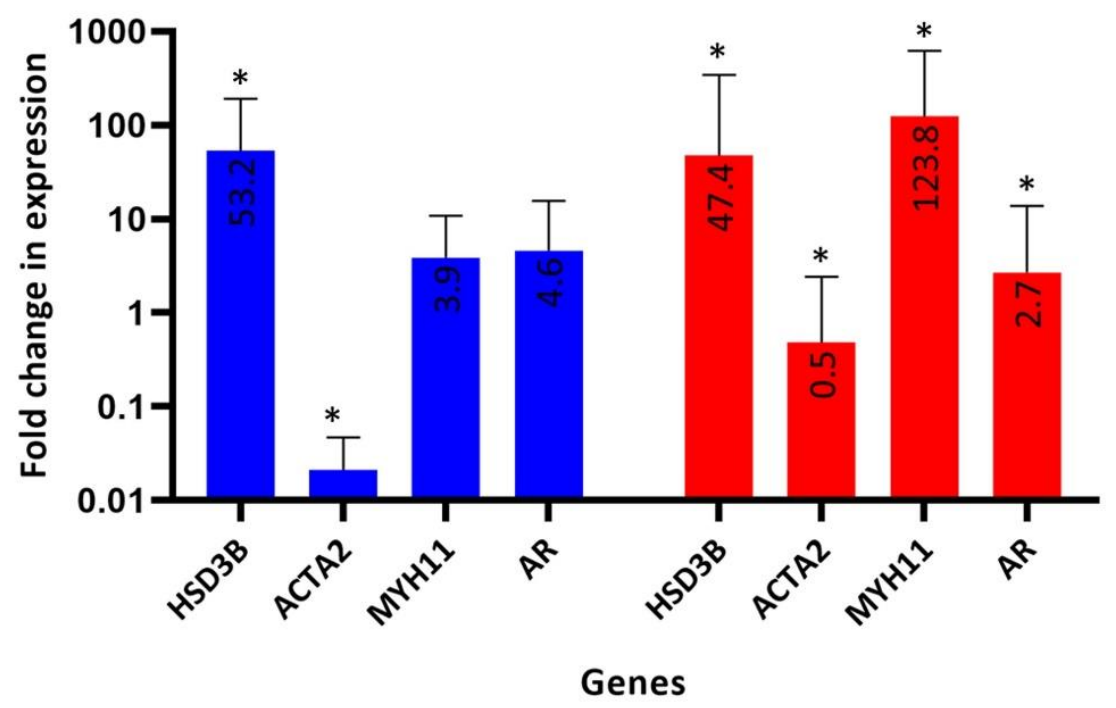


bioRxiv preprint doi: https://doi.org/10.1101/2021.06.04.447123; this version posted July 13, 2021. The copyright holder for this preprint (which was not certified by peer review) is the author/funder, who has granted bioRxiv a license to display the preprint in perpetuity. It is made available under aCC-BY-ND 4.0 International license.

\section{In vitro Differentiation of Peritubular Myoid Cells}

Figure 4. Gene expression of the PDGFBB and PDGFAA-derived cells. A) Fold change in gene expression in the PDGFBB-derived cells compared to the PDGFAA-derived cells. B) Fold change in gene expression in the PDGFBB-derived and PDGFAA-derived cells compared to the primary Sertoli cells. * indicates statistical significance. Abbreviations: HSD3B = Hydroxy-Delta-5-Steroid Dehydrogenase, 3 Beta- And Steroid DeltaIsomerase 1, ACTA2 = Actin Alpha 2, Smooth Muscle, MYH11 = Myosin Heavy Chain 11, AR = Androgen Receptor, PDGFAA = Platelet-Derived Growth Factor-AA, PDGFBB = Platelet-Derived Growth Factor-BB.

\section{DISCUSSION}

In this study we derived PTM-like cells from hiPSCs and showed that the acquisition of their smooth muscle phenotype is dependent upon PDGFBB signaling. Furthermore, this derivation method mirrors what we know about in vivo patterning of Leydig and PTMs based on animal lineage tracing studies and animal knock-out models,(Gnessi, et al., 1995, Ye, Li, Li, Chen and Ge, 2017) suggesting its usefulness as a human developmental model. Indeed, the derivation of Leydig-like cells and PTM-like cells through the use of either PDGFAA or PDGFBB signaling using an otherwise identical patterning method highlights the closely related lineage between Leydig cells and PTMs, and is in agreement with recent single cell sequencing findings showing that human Leydig cells and PTMs arise from a shared progenitor.(Guo, Nie, Giebler, Mlcochova, Wang, Grow, DonorConnect, Kim, Tharmalingam, Matilionyte, Lindskog, Carrell, Mitchell, Goriely, Hotaling and Cairns, 2020) Furthermore, at the time of preparing this manuscript, another study was published showing that PDGFAA and PDGFBB delineate Leydig cell and PTM fates from the SLC progenitor stage in rat seminiferous tubule cultures.(Zhao, et al., 2021)

hPTM phenotypes were noted to possess immature gene expression of the differentiating marker Nestin and the progenitor marker CD90. Whether this was a result of missing microenvironmental factors necessary to mature PTMs or a consequence of PTM plasticity in response to unnatural in 


\section{In vitro Differentiation of Peritubular Myoid Cells}

vitro culture conditions requires further investigation, but also highlights how little is currently understood regarding the effects of in vitro culture conditions on the PTM phenotype. Optimal human PTM culture conditions have not yet been explored due to their limited availability for research, with current models employing basic cell culture conditions including attachment onto 2-dimensional treated plastic surfaces, and growth in fetal bovine serum (FBS)-supplemented medium,(Albrecht, et al., 2006) leaving room for substantial improvements. In particular, 3dimensional cultures are proving to be more useful model systems than 2-dimensional cultures by promoting biomimetic cell-cell and cell-matrix interactions, leading to more accurate data and greater insights.(Jensen and Teng, 2020) Indeed, a singular study of in vitro culture conditions for PTM culture showed that seminiferous tubule-derived extracellular matrix promoted an in vivolike PTM histology whereas isolated components could not, suggesting that their correct histology depends upon a specific biomatrix.(Tung and Fritz, 1986) Another improvement to be explored could be replacement of FBS by a chemically defined or xeno-free medium for greater control over experimental variables, avoidance of batch-to-batch variability, and for ethical reasons.(Gstraunthaler, 2003, Gstraunthaler, et al., 2013, Jayme, et al., 1988, Witzeneder, et al., 2013) Because of its ill-defined composition of animal hormones, growth factors, and proteins, the use of FBS in current PTM models imparts unknowable and variable effects on the cells, limiting their experimental reproducibility and accuracy.

Animal and human studies have identified PTMs as critical to fertility and normal development, however differences in animal testicular development and cytoarchitecture(Guo, Nie, Giebler, Mlcochova, Wang, Grow, DonorConnect, Kim, Tharmalingam, Matilionyte, Lindskog, Carrell, Mitchell, Goriely, Hotaling and Cairns, 2020, Mayerhofer, 2013) suggest a need for complementary human models to gain further insight into human testicular development and 


\section{In vitro Differentiation of Peritubular Myoid Cells}

causes of infertility. Until human primary peritubular myoid cells become more accessible to researchers, hPTMs could represent an alternative to bridge this gap in our understanding of their phenotype and functionality. While further characterization of hPTMs in terms of global gene expression profiling and functionality will better define the limitations, if any, with respect to how they can be used to model primary human PTMs, their potential to model some aspects of PTMs is readily apparent by their in vivo-like patterning, and their expression of smooth muscle and androgen receptor genes. For example, rodent PTM androgen receptor knock-out models show that Leydig cell differentiation and functionality is dependent on PTM androgen receptor-mediated activity,(Welsh, Moffat, Belling, de Franca, Segatelli, Saunders, Sharpe and Smith, 2012) while human studies have discovered a correlation between improperly differentiated Leydig cells and PTMs with testis cancer, Sertoli Cell Only (SCO) syndrome and Klinefelter syndrome.(Cina and Flannigan, 2020, Lottrup, et al., 2014, Winge, et al., 2018) The hPTM protocol presented here has the potential to model the relationship between PTMs and Leydig cells during their development.

The limitless supply of hPTMs also makes them a suitable cellular source for high throughput toxicity screening. The effect of environmental toxicants such as pesticides, dioxins, polychlorinated biphenyls, phthalates, alkylphenols and bisphenol A are known to alter reproductive function, and toxicology studies on rodents show that PTM development and function are highly susceptible.(Johnson, et al., 2007, Lara, et al., 2017, Saldutti, et al., 2013, Silvestroni, et al., 1999) Furthermore, patient-specific hiPSC-derived testis cells allows for non-invasive disease modelling for severe infertility conditions such as non-obstructive azoospermia. Now, with the addition of hPTMs to the previously described hiPSC-derived Leydig, Sertoli, and spermatogonial stem cells, 3-D modelling of spermatogenesis and the spermatogenic niche can be modelled and evaluated. 


\section{CONCLUSION}

Our novel differentiation method produces PTM-like cells as indicated by their morphology, protein expression, and gene expression. These cells will allow for ongoing understanding of the cellular interactions required for normal spermatogenesis in an in vitro setting. Furthermore, this method mirrors in vivo signaling necessary for the derivation of Leydig cell and PTM fates, opening the door for developmental studies.

\section{ACKNOWLEDGEMENTS}

The authors would like to acknowledge the Vancouver Prostate Centre for their financial support, and the Lange Lab at the Vancouver Prostate Centre for their technical support.

\section{DECLARATIONS}

\section{Funding}

This study was funded by the Vancouver Prostate Centre.

\section{Conflicts of Interest}

The authors of this study have no potential conflicts of interest to disclose.

\section{Ethics Approval}

This study was performed in line with the principles of the Declaration of Helsinki. Approval was granted by the University of British Columbia Clinical Research Ethics Board (CREB approved protocol H18-03543). Experiments using hiPSCs in this study were not subject to ethics approval from the University of British Columbia Clinical Research Ethics Boards or Stem Cell Oversight Committee, since they were derived from somatic cells and not intended for transfer into humans or non-human animals.

\section{Consent to Participate}

Human samples were obtained with informed consent and anonymized as per CREB protocol H1803543. 
In vitro Differentiation of Peritubular Myoid Cells

\section{Availability of Data and Material}

The data that support the findings of this study are available from the corresponding author upon

reasonable request.

\section{Code Availability}

Not applicable.

\section{Authors' Contributions}

Meghan Robinson: conceptualization, methodology, validation, formal analyses, investigation, writing -

original draft, writing - review \& editing, visualization. Luke Witherspoon: writing - original draft, writing

- review \& editing. Stephanie Willerth: resources, writing - review \& editing, supervision. Ryan Flannigan:

conceptualization, resources, writing - review \& editing, supervision, project administration, funding

acquisition.

\section{REFERENCES}

Albrecht M, Ramsch R, Kohn FM, Schwarzer JU, Mayerhofer A (2006) Isolation and cultivation of human testicular peritubular cells: a new model for the investigation of fibrotic processes in the human testis and male infertility. J Clin Endocrinol Metab 91:1956-1960

Bernal A, Arranz L (2018) Nestin-expressing progenitor cells: function, identity and therapeutic implications. Cell Mol Life Sci 75:2177-2195

Chen LY, Willis WD, Eddy EM (2016) Targeting the Gdnf Gene in peritubular myoid cells disrupts undifferentiated spermatogonial cell development. Proc Natl Acad Sci U S A 113:1829-1834

Chen P, Zirkin BR, Chen H (2020) Stem Leydig Cells in the Adult Testis: Characterization, Regulation and Potential Applications. Endocr Rev 41:

Chen X, Li C, Chen Y, Xi H, Zhao S, Ma L, Xu Z, Han Z, Zhao J, Ge R, Guo X (2019) Differentiation of human induced pluripotent stem cells into Leydig-like cells with molecular compounds. Cell Death Dis 10:220

Chiarenza C, Filippini A, Tripiciano A, Beccari E, Palombi F (2000) Platelet-derived growth factor-BB stimulates hypertrophy of peritubular smooth muscle cells from rat testis in primary cultures. Endocrinology 141:29712981

Chui K, Trivedi A, Cheng CY, Cherbavaz DB, Dazin PF, Huynh AL, Mitchell JB, Rabinovich GA, Noble-Haeusslein L, John CM (2011) Characterization and functionality of proliferative human Sertoli cells. Cell Transplant 20:619635

Cina DP, Flannigan R (2020) Failing to mature: somatic cell dysfunction in the spermatogenic niche among patients with Sertoli cell-only and Klinefelter syndromes. Fertil Steril 113:1155-1156

De Gendt K, Atanassova N, Tan KA, de Franca LR, Parreira GG, McKinnell C, Sharpe RM, Saunders PT, Mason Jl, Hartung S, Ivell R, Denolet E, Verhoeven G (2005) Development and function of the adult generation of Leydig cells in mice with Sertoli cell-selective or total ablation of the androgen receptor. Endocrinology 146:4117-4126 
In vitro Differentiation of Peritubular Myoid Cells

Gnessi L, Basciani S, Mariani S, Arizzi M, Spera G, Wang C, Bondjers C, Karlsson L, Betsholtz C (2000) Leydig cell loss and spermatogenic arrest in platelet-derived growth factor (PDGF)-A-deficient mice. J Cell Biol 149:10191026

Gnessi L, Emidi A, Jannini EA, Carosa E, Maroder M, Arizzi M, Ulisse S, Spera G (1995) Testicular development involves the spatiotemporal control of PDGFs and PDGF receptors gene expression and action. J Cell Biol 131:11051121

Gnessi L, Emidi A, Scarpa S, Palleschi S, Ragano-Caracciolo M, Silvestroni L, Modesti A, Spera G (1993) Platelet-derived growth factor effects on purified testicular peritubular myoid cells: binding, cytosolic Ca2+ increase, mitogenic activity, and extracellular matrix production enhancement. Endocrinology 133:1880-1890

Gstraunthaler G (2003) Alternatives to the use of fetal bovine serum: serum-free cell culture. ALTEX 20:275-281

Gstraunthaler G, Lindl T, van der Valk J (2013) A plea to reduce or replace fetal bovine serum in cell culture media. Cytotechnology 65:791-793

Guan X, Chen P, Zhao X, Hao X, Chen F, Ji M, Wen X, Lin H, Ye L, Chen H (2019) Characterization of stem cells associated with seminiferous tubule of adult rat testis for their potential to form Leydig cells. Stem Cell Res 41:101593

Guo J, Nie X, Giebler M, Mlcochova H, Wang Y, Grow EJ, DonorConnect, Kim R, Tharmalingam M, Matilionyte G, Lindskog C, Carrell DT, Mitchell RT, Goriely A, Hotaling JM, Cairns BR (2020) The Dynamic Transcriptional Cell Atlas of Testis Development during Human Puberty. Cell Stem Cell 26:262-276 e264

Guo Y, Hai Y, Yao C, Chen Z, Hou J, Li Z, He Z (2015) Long-term culture and significant expansion of human Sertoli cells whilst maintaining stable global phenotype and AKT and SMAD1/5 activation. Cell Commun Signal $13: 20$

Jarvi K, Lo K, Grober E, Mak V, Fischer A, Grantmyre J, Zini A, Chan P, Patry G, Chow V, Domes T (2015) The workup and management of azoospermic males. Can Urol Assoc J 9:229-235

Jayme DW, Epstein DA, Conrad DR (1988) Fetal bovine serum alternatives. Nature 334:547-548

Jensen C, Teng Y (2020) Is It Time to Start Transitioning From 2D to 3D Cell Culture? Front Mol Biosci 7:

Johnson KJ, Hensley JB, Kelso MD, Wallace DG, Gaido KW (2007) Mapping gene expression changes in the fetal rat testis following acute dibutyl phthalate exposure defines a complex temporal cascade of responding cell types. Biology of Reproduction 77:978-989

Ketola I, Pentikainen V, Vaskivuo T, Ilvesmaki V, Herva R, Dunkel L, Tapanainen JS, Toppari J, Heikinheimo M (2000) Expression of transcription factor GATA-4 during human testicular development and disease. J Clin Endocrinol Metab 85:3925-3931

Lam AQ, Freedman BS, Morizane R, Lerou PH, Valerius MT, Bonventre JV (2014) Rapid and efficient differentiation of human pluripotent stem cells into intermediate mesoderm that forms tubules expressing kidney proximal tubular markers. J Am Soc Nephrol 25:1211-1225

Lara NLM, van den Driesche S, Macpherson S, Franca LR, Sharpe RM (2017) Dibutyl phthalate induced testicular dysgenesis originates after seminiferous cord formation in rats. Sci Rep-Uk 7:

Li X, Wang Z, Jiang Z, Guo J, Zhang Y, Li C, Chung J, Folmer J, Liu J, Lian Q, Ge R, Zirkin BR, Chen H (2016) Regulation of seminiferous tubule-associated stem Leydig cells in adult rat testes. Proc Natl Acad Sci U S A 113:26662671

Liu C, Rodriguez K, Yao HH (2016) Mapping lineage progression of somatic progenitor cells in the mouse fetal testis. Development 143:3700-3710

Liu G, David BT, Trawczynski M, Fessler RG (2020) Advances in Pluripotent Stem Cells: History, Mechanisms, Technologies, and Applications. Stem Cell Rev Rep 16:3-32

Losinno AD, Morales A, Fernandez D, Lopez LA (2012) Peritubular myoid cells from rat seminiferous tubules contain actin and myosin filaments distributed in two independent layers. Biol Reprod 86:150, 151-158

Lottrup G, Nielsen JE, Maroun LL, Moller LM, Yassin M, Leffers H, Skakkebaek NE, Rajpert-De Meyts E (2014) Expression patterns of DLK1 and INSL3 identify stages of Leydig cell differentiation during normal development and in testicular pathologies, including testicular cancer and Klinefelter syndrome. Hum Reprod 29:1637-1650

Malki S, Berta P, Poulat F, Boizet-Bonhoure B (2005) Cytoplasmic retention of the sex-determining factor SOX9 via the microtubule network. Exp Cell Res 309:468-475 
In vitro Differentiation of Peritubular Myoid Cells

Mayer C, Adam M, Walenta L, Schmid N, Heikela H, Schubert K, Flenkenthaler F, Dietrich KG, Gruschka S, Arnold GJ, Frohlich T, Schwarzer JU, Kohn FM, Strauss L, Welter H, Poutanen M, Mayerhofer A (2018) Insights into the role of androgen receptor in human testicular peritubular cells. Andrology 6:756-765

Mayerhofer A (2013) Human testicular peritubular cells: more than meets the eye. Reproduction 145:R107-116

Meroni SB, Galardo MN, Rindone G, Gorga A, Riera MF, Cigorraga SB (2019) Molecular Mechanisms and Signaling Pathways Involved in Sertoli Cell Proliferation. Front Endocrinol (Lausanne) 10:224

Mishra J, Gautam M, Dadhich R, Kowtharapu BS, Majumdar SS (2012) Peritubular cells may modulate Leydig cellmediated testosterone production through a nonclassic pathway. Fertil Steril 98:1308-1317 e1301

Norton JN, Skinner MK (1989) Regulation of Sertoli cell function and differentiation through the actions of a testicular paracrine factor P-Mod-S. Endocrinology 124:2711-2719

Odeh HM, Kleinguetl C, Ge R, Zirkin BR, Chen H (2014) Regulation of the proliferation and differentiation of Leydig stem cells in the adult testis. Biol Reprod 90:123

Saldutti LP, Beyer BK, Breslin W, Brown TR, Chapin RE, Campion S, Enright B, Faustman E, Foster PMD, Hartung T, Kelce W, Kim JH, Loboa EG, Piersma AH, Seyler D, Turner KJ, Yu H, Yu XZ, Sasaki JC (2013) In Vitro Testicular Toxicity Models: Opportunities for Advancement via Biomedical Engineering Techniques. Altex-Altern Anim Ex 30:353-377

Silvestroni L, Rossi F, Magnanti M, Lubrano C, Santiemma V, Palleschi S (1999) A novel aspect of lindane testicular toxicity: in vitro effects on peritubular myoid cells. Reprod Toxicol 13:431-441

Skinner MK, Fritz IB (1985) Testicular peritubular cells secrete a protein under androgen control that modulates Sertoli cell functions. Proc Natl Acad Sci U S A 82:114-118

Takahashi K, Tanabe K, Ohnuki M, Narita M, Ichisaka T, Tomoda K, Yamanaka S (2007) Induction of pluripotent stem cells from adult human fibroblasts by defined factors. Cell 131:861-872

Tung PS, Fritz IB (1986) Cell-substratum and cell-cell interactions promote testicular peritubular myoid cell histotypic expression in vitro. Dev Biol 115:155-170

Viger RS, Mertineit C, Trasler JM, Nemer M (1998) Transcription factor GATA-4 is expressed in a sexually dimorphic pattern during mouse gonadal development and is a potent activator of the Mullerian inhibiting substance promoter. Development 125:2665-2675

Wang RS, Yeh S, Tzeng CR, Chang C (2009) Androgen receptor roles in spermatogenesis and fertility: lessons from testicular cell-specific androgen receptor knockout mice. Endocr Rev 30:119-132

Welsh M, Moffat L, Belling K, de Franca LR, Segatelli TM, Saunders PT, Sharpe RM, Smith LB (2012) Androgen receptor signalling in peritubular myoid cells is essential for normal differentiation and function of adult Leydig cells. Int J Androl 35:25-40

Welter H, Kampfer C, Lauf S, Feil R, Schwarzer JU, Kohn FM, Mayerhofer A (2013) Partial loss of contractile marker proteins in human testicular peritubular cells in infertility patients. Andrology 1:318-324

WiCell (2021) iPS(Foreskin)-1. vol 2021. WiCell

Wilhelm D, Palmer S, Koopman P (2007) Sex determination and gonadal development in mammals. Physiol Rev 87:128

Winge SB, Dalgaard MD, Belling KG, Jensen JM, Nielsen JE, Aksglaede L, Schierup MH, Brunak S, Skakkebaek NE, Juul A, Rajpert-De Meyts E, Almstrup K (2018) Transcriptome analysis of the adult human Klinefelter testis and cellularity-matched controls reveals disturbed differentiation of Sertoli- and Leydig cells. Cell Death Dis 9:586

Witzeneder K, Lindenmair A, Gabriel C, Holler K, Theiss D, Redl H, Hennerbichler S (2013) Human-derived alternatives to fetal bovine serum in cell culture. Transfus Med Hemother 40:417-423

Ye L, Li X, Li L, Chen H, Ge RS (2017) Insights into the Development of the Adult Leydig Cell Lineage from Stem Leydig Cells. Front Physiol 8:430

Zhao XX, Wen X, Ji MP, Guan XJ, Chen PP, Hao XR, Chen FF, Hu Y, Duan P, Ge RS, Chen HL (2021) Differentiation of seminiferous tubule-associated stem cells into leydig cell and myoid cell lineages. Mol Cell Endocrinol 525: 